\title{
Impact of Periampullary Diverticulum on ERCP Performance: A Matched Case-Control Study
}

\author{
Juan E. Corral, Omar Y. Mousa, Paul T. Kröner, Victoria Gomez and Frank J. Lukens \\ Division of Gastroenterology and Hepatology, Mayo Clinic, Jacksonville, FL, USA
}

Background/Aims: Periampullary diverticulum $(\mathrm{PAD})$ is frequently encountered during endoscopic retrograde cholangiopancreatography (ERCP) and has been associated with stone formation in the bile duct. The effects of PAD on the ERCP procedure have been often debated. We aimed to compare the therapeutic success of ERCP between patients with PAD and matched controls.

Methods: We reviewed all ERCPs with findings of PAD in a national database $(n=1,089)$ and compared them with age- and gendermatched controls in a 1:3 fashion $(n=3,267)$. Demographics, endoscopic findings, visualization of main structures, and therapeutic success rates were compared between groups. Secondary analysis compared PAD cases and controls who had gallstone disease.

Results: The average cohort age was $68.4 \pm 14.3$ years and $55.1 \%$ were male. ERCP success was similar in both groups, and no significant inter-group differences were found in the multivariate analysis. The presence of PAD did not affect the rates of sphincterotomy or visualization of main biliary structures. Secondary analysis showed similar success rates for gallstone removal between patients with $\mathrm{PAD}$ and controls.

Conclusions: PAD may not be considered a hinderance to ERCP success. Further research is needed to determine the best approach to cannulate the ampulla and provide endoscopic therapy for different subtypes of PAD. Clin Endosc 2019;52:65-71

Key Words: Cholangiopancreatography, endoscopic retrograde; Periampullary diverticulum; Duodenal diverticulum

\section{INTRODUCTION}

Periampullary diverticulum (PAD) is an outpouching of $2-3 \mathrm{~cm}$ within the ampulla that develops with aging. ${ }^{1,2}$ It is usually found incidentally during endoscopic retrograde cholangiopancreatography (ERCP) in 3\%-32\% patients. ${ }^{2-5} \mathrm{PAD}$ can interfere with biliary drainage and has been associated with the development of bile duct stones, gallstones, and acute cholangitis. ${ }^{2,6}$

PAD is classified in relation to the papilla location. Boix et

Received: April 25, 2018 Revised: June 15, 2018

Accepted: June 19, 2018

Correspondence: Juan E. Corral

Division of Gastroenterology and Hepatology, Mayo Clinic, 4500 San Pablo Road, Jacksonville, FL 32224, USA

Tel: +1-904-953-2000, Fax: +1-904-953-6225, E-mail: corral.juan@mayo.edu

ORCID: https://orcid.org/0000-0002-8821-4534

(c) This is an Open Access article distributed under the terms of the Creative Commons Attribution Non-Commercial License (http://creativecommons.org/ licenses/by-nc/3.0) which permits unrestricted non-commercial use, distribution and reproduction in any medium, provided the original work is properly cited. al. proposed three groups: type I if the papilla is found inside the diverticulum, type II if it is in the margin of the diverticulum, and type III if it is near the diverticulum. ${ }^{7}$ Panteris et al. simplified the classification in two groups: type A when the papilla is in the rim or within $2 \mathrm{~cm}$ from the edge of the diverticulum (types II and III), and type B if the papilla is inside the diverticulum or between two adjacent diverticula (type I). ${ }^{5}$

There is conflicting data on whether the presence of PAD affects the therapeutic success rates during ERCP. Initial studies from the 1980s and 1990s suggested that PAD may prolong the procedure time and increase complication rates. ${ }^{4,89}$ More recently, two large retrospective case-control studies and two prospective studies showed no difference in biliary cannulation rates and stone extraction success between patients with PAD and those without. ${ }^{2,5,6,10}$ Panteris et al. suggested that PAD may even be an indicator of easier biliary cannulation, provided that the major papilla is found easily. ${ }^{5}$

In the present study, we aimed to compare ERCP performance between patients with PAD and age- and gen- 
der-matched controls by using a US national database. ${ }^{2,10}$ The primary objective was to compare ERCP therapeutic success between the cases and controls, while the secondary objective was to determine whether the findings were different for patients with gallstone disease.

\section{MATERIALS AND METHODS}

Our team requested access to the Clinical Outcomes Research Initiative (CORI) database from the National Institute of Diabetes and Digestive and Kidney Diseases Central Repository. ${ }^{11}$ The CORI was launched in 1995 and is the largest multi-center endoscopic database in the US. Approximately 500 physicians from 65 adult and 12 pediatric practice sites submit more than 250,000 reports annually to a central data repository. The practice sites include private practice (70\%-75\% of the reports), academic sites (10\%-15\%), and Veterans Affairs sites (11\%). They were selected to represent a complete spectrum of gastroenterology practices and include both urban and rural sites across the US. Approximately 95\% of procedures reported by the CORI are performed in outpatient settings. The CORI Endoscopic Reporting Software has two major versions, V3 and V4, which were in use from 2000 to 2012 and 2012-2014, respectively. Additional details about CORI can be found elsewhere. ${ }^{11}$

The CORI database V3 was reviewed to capture all ERCP procedures that reported PAD between January 2000 and December 2012. ${ }^{11}$ ERCP cases in adults ( $\geq 18$ years) with PAD were included if the endoscopist had selected duodenal diverticulum as a finding or diagnosis according to the CORI soft- ware. Patients were included if their age and gender and a description of major papilla visualization (achieved or not) were available. We removed repeated procedures performed in the same patient if two procedures had the same patient identifier number. Patients with PAD were compared with age- and gender-matched controls who were selected randomly using a 1:3 fashion from all other ERCPs, regardless of the indication for the procedure. Demographic variables, procedure time (i.e., from scope insertion to withdrawal), fluoroscopy time, endoscopic and fluoroscopic findings (e.g., visualization of the common bile duct and pancreatic duct), and therapeutic success (e.g., stone extraction determined by the endoscopist) were compared between the groups. ERCP complications and medication use are not consistently recorded in this database and were not included in our study design.

Secondary analysis was performed for patients with gallstone disease. Cases where selected if $\mathrm{PAD}$ and gallstones were reported in the indications or findings section in the CORI software. Controls were selected randomly in a 1:1 fashion matched according to age, gender, and the presence of gallstones from the initial database (all indications).

Ordinal variables were compared using Pearson's chi-square test and continuous variables, using a standard $t$-test (unpaired test for means). Univariate regression was performed, followed by a multivariate regression model with significant variables $(p<0.05)$. Odds ratios and adjusted odds ratio were reported for each variable. For logistic regression, we only included procedures that had complete information on the variable of interest, namely, "ERCP success". Data were analyzed using Stata $\mathrm{SE}^{\circledR} 13.0$ (College Station, TX, USA). Our research protocol was exempt from a formal institutional review board

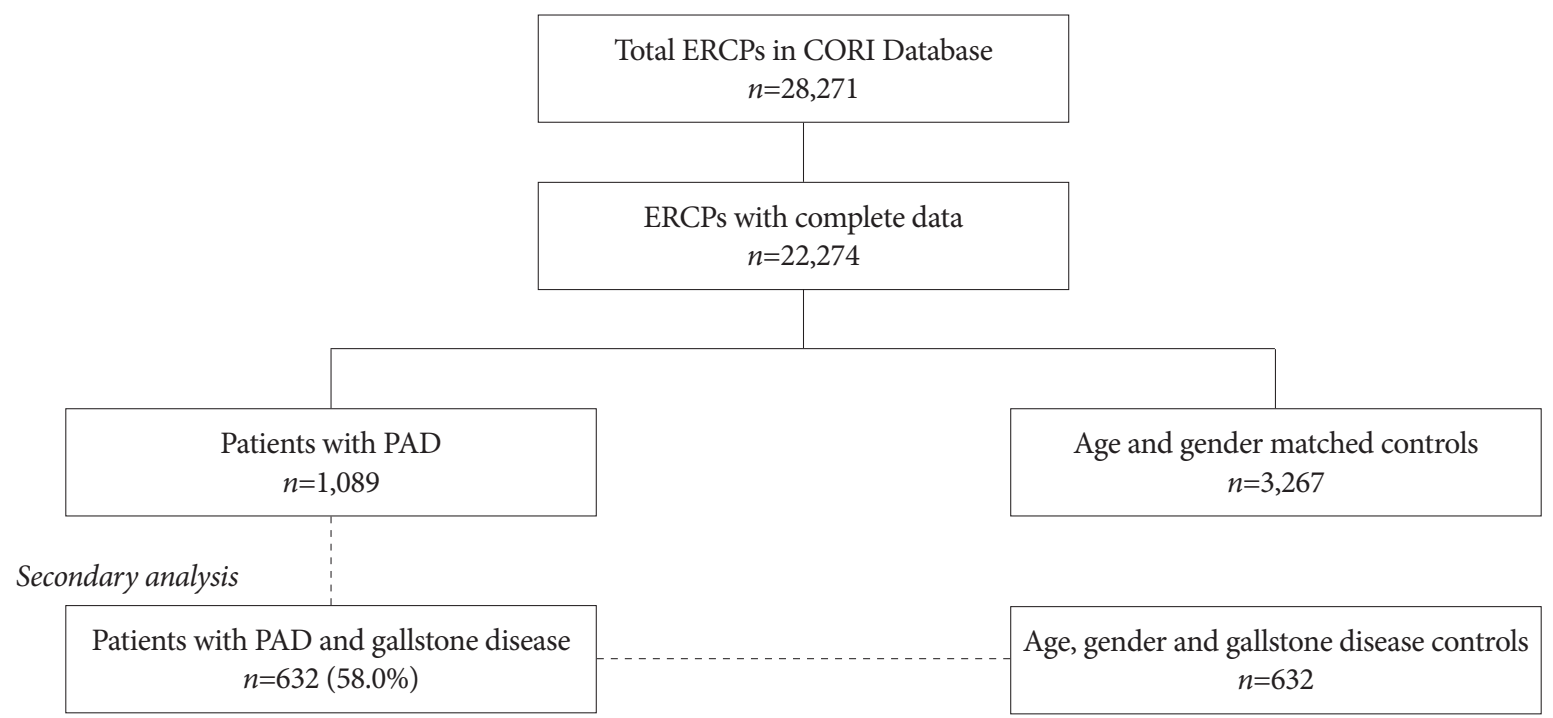

Fig. 1. Study flow diagram. ERCP, endoscopic retrograde cholangiopancreatography; CORI, Clinical Outcomes Research Initiative; PAD, periampullary diverticulum. 
approval (since it involved analysis of de-identified information).

\section{RESULTS}

An initial CORI database review revealed 28,271 ERCPs in the study period. PAD was reported in 1,325 (4.7\%) of these cases ( $8.6 \%$ in patients $\geq 70$ years old). We identified 1,089 PAD cases with complete information and selected 3,267 matched controls for comparison (Fig. 1). The average age of the entire cohort was $68.4 \pm 14.3$ years, and 2,400 (55.1\%) were male. Most patients were white $(1,545$ [65.9\%]) and non-Hispanic $(3,933$ [90.8\%]). Forty-two percent patients with PAD underwent ERCP as outpatients, while 52\% of the controls underwent ERCP as outpatients. The anesthesia risk score

Table 1. Patient Demographics, ERCP Indications and Success $(n=4,356)$

\begin{tabular}{|c|c|c|c|c|}
\hline & & $\begin{array}{c}\text { Periampullary diverticulum } \\
n=1,089(\%)\end{array}$ & $\begin{array}{c}\text { Controls } \\
n=3,267(\%)\end{array}$ & $p$-value \\
\hline Age & Mean $y r \pm S D$ & $68.4 \pm 14.3$ & $68.4 \pm 14.3$ & - \\
\hline Gender & Male (\%) & $600(55.1)$ & $1,800(55.1)$ & - \\
\hline Ethnicity & $\begin{array}{l}\text { White } \\
\text { Black } \\
\text { Native American } \\
\text { Other }\end{array}$ & $\begin{array}{l}965(89.0) \\
31(2.9) \\
65(6.0) \\
23(2.1)\end{array}$ & $\begin{array}{c}2,838(87.3) \\
231(7.1) \\
103(3.2) \\
78(2.4)\end{array}$ & $<0.001$ \\
\hline ASA risk class & $\begin{array}{l}\text { I } \\
\text { II } \\
\text { III } \\
\text { IV-V }\end{array}$ & $\begin{array}{c}85(8.5) \\
527(52.9) \\
355(35.6) \\
29(2.9)\end{array}$ & $\begin{array}{r}308(10.7) \\
1,461(50.9) \\
1,001(34.9) \\
100(3.5)\end{array}$ & 0.18 \\
\hline Setting & $\begin{array}{l}\text { Outpatient } \\
\text { Inpatient ward } \\
\text { ICU }\end{array}$ & $\begin{array}{c}436(42.5) \\
557(54.3) \\
33(3.2)\end{array}$ & $\begin{array}{c}1,476(51.5) \\
1,282(44.7) \\
111(3.9)\end{array}$ & $<0.001$ \\
\hline Indications and findings $\mathrm{s}^{\mathrm{b})}$ & $\begin{array}{l}\text { Bile stone/Sludge } \\
\text { Stent }^{\text {c) }} \\
\text { Obstructive jaundice } \\
\text { Cholangitis } \\
\text { Pancreatitis } \\
\text { Cancer }^{\text {d) }}\end{array}$ & $\begin{array}{c}630(57.8) \\
355(32.6) \\
370(34.0) \\
188(17.3) \\
45(4.1) \\
7(0.6)\end{array}$ & $\begin{array}{c}1,283(39.3) \\
1,613(49.4) \\
1,126(34.5) \\
341(10.4) \\
183(5.6) \\
85(2.6)\end{array}$ & $\begin{array}{c}<0.001 \\
<0.001 \\
0.8 \\
<0.001 \\
0.06 \\
<0.001\end{array}$ \\
\hline Time & $\begin{array}{l}\text { Average procedure time ( } \mathrm{min}) \\
\text { Average fluoroscopy time (min) }\end{array}$ & $\begin{array}{r}39.1 \pm 27.1 \\
7.1 \pm 17.3\end{array}$ & $\begin{array}{r}42.4 \pm 25.7 \\
7.2 \pm 11.8\end{array}$ & $\begin{array}{l}0.001 \\
0.8\end{array}$ \\
\hline Common bile duct visualization & $\begin{array}{l}\text { Visualized } \\
\text { Not visualized } \\
\text { Not sought }\end{array}$ & $\begin{aligned} 1,011 & (92.8) \\
74 & (6.8) \\
4 & (0.4)\end{aligned}$ & $\begin{array}{c}2,971(90.9) \\
235(7.2) \\
61(1.9)\end{array}$ & 0.002 \\
\hline Pancreatic duct visualization & $\begin{array}{l}\text { Visualized } \\
\text { Not visualized } \\
\text { Not sought }\end{array}$ & $\begin{array}{l}361(35.9) \\
100(10.0) \\
544(54.1)\end{array}$ & $\begin{array}{r}1,142(39.3) \\
319(11.0) \\
1,446(49.7)\end{array}$ & 0.06 \\
\hline Minor papilla visualization & $\begin{array}{l}\text { Visualized } \\
\text { Not visualized } \\
\text { Not sought }\end{array}$ & $\begin{array}{c}93(12.2) \\
71(9.3) \\
597(78.5)\end{array}$ & $\begin{array}{c}309(13.5) \\
218(9.5) \\
1,763(76.7)\end{array}$ & 0.8 \\
\hline Sphincterotomy & Performed & $690(63.4)$ & $1,573(48.1)$ & $<0.001$ \\
\hline $\begin{array}{l}\text { ERCP } \\
\text { therapeutic success }\end{array}$ & $\begin{array}{l}\text { Successful } \\
\text { Unsuccessful } \\
\text { Cannot be established }\end{array}$ & $\begin{array}{c}691(55.5) \\
37(3.4) \\
361(33.1)\end{array}$ & $\begin{aligned} 1,727 & (52.9) \\
72 & (2.2) \\
1,468 & (44.9)\end{aligned}$ & $<0.001$ \\
\hline
\end{tabular}

ERCP, endoscopic retrograde cholangiopancreatography; SD, standard deviation; ASA, American Society of Anesthesiologists; ICU, intensive care unit; PAD, periampullary diverticulum.

${ }^{a)}$ Only 3 patients were considered Class V.

${ }^{\text {b) }}$ These categories are not mutually exclusive.

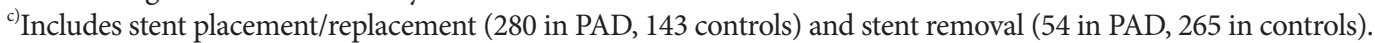

${ }^{\mathrm{d})}$ Includes biliary, pancreatic or ampullary cancer. 
Table 2. Crude and Adjusted Odds Ratios for Factors Associated with Periampullary Diverticulum $(n=4,356)$

\begin{tabular}{|c|c|c|c|}
\hline & & $\begin{array}{c}\text { Crude OR } \\
(95 \% \text { CI })\end{array}$ & $\begin{array}{l}\text { Adjusted OR } \\
(95 \% \mathrm{CI})\end{array}$ \\
\hline \multirow[t]{4}{*}{ Ethnicity } & White & 1 & N/A \\
\hline & Black & $0.39(0.27-0.58)$ & \\
\hline & Native American & $1.86(1.35-2.55)$ & \\
\hline & Other & $0.87(0.54-1.39)$ & \\
\hline \multirow[t]{4}{*}{ ASA risk class } & I & 1 & N/A \\
\hline & II & $1.30(1.01-1.70)$ & \\
\hline & III & $1.29(0.98-1.68)$ & \\
\hline & $\mathrm{IV}-\mathrm{V}^{\mathrm{b})}$ & $1.05(0.65-1.69)$ & \\
\hline \multirow[t]{3}{*}{ Setting } & Outpatient & 1 & 1 \\
\hline & Inpatient & $1.47(1.27-1.70)$ & $1.13(0.93-1.38)$ \\
\hline & ICU & $1.00(0.67-1.51)$ & $0.64(0.38-1.07)$ \\
\hline \multirow[t]{2}{*}{ Procedure time $\mathrm{e}^{\mathrm{a})}$} & $\leq 30 \mathrm{~min}$ & 1 & 1 \\
\hline & $>30 \mathrm{~min}$ & $0.70(0.70-0.94)$ & $0.76(0.63-0.92)$ \\
\hline \multirow[t]{2}{*}{ Bile stone/Sludge $^{\text {a) }}$} & Other indications & 1 & 1 \\
\hline & Bile stone/Sludge & $2.12(1.84-2.44)$ & $1.70(1.38-2.09)$ \\
\hline \multirow[t]{2}{*}{ Stent $^{\mathrm{a}, \mathrm{c})}$} & No stents & 1 & 1 \\
\hline & Placement, replacement or removal & $0.50(0.43-0.57)$ & $0.65(0.53-0.80)$ \\
\hline \multirow[t]{2}{*}{ Sphincterotomy ${ }^{\text {a) }}$} & Not performed & 1 & 1 \\
\hline & Performed & $1.86(1.61-2.14)$ & $1.27(1.02-1.58)$ \\
\hline \multirow[t]{2}{*}{ ERCP therapeutic success } & Unsuccessful & 1 & 1 \\
\hline & Successful & $0.78(0.52-1.17)$ & $0.63(0.39-1.00)$ \\
\hline
\end{tabular}

OR, odds ratio; CI, confidence interval; N/A, not available; ASA, American Society of Anesthesiologists; ICU, intensive care unit; ERCP, endoscopic retrograde cholangiopancreatography.

a) Statistically significant in multivariate analysis $(p<0.05)$.

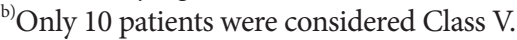

${ }^{c)}$ Includes stent placement, replacement or removal.

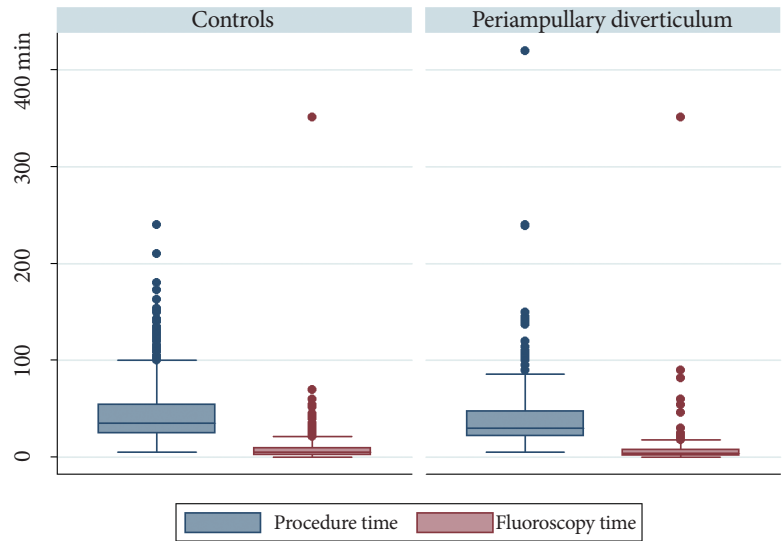

Fig. 2. Procedure time and fluoroscopy time in periampullary diverticulum patients and controls.

was similar between the groups (Table 1). Biliary stones (i.e., choledocolithiasis, cholelithiasis, or biliary pancreatitis) were twice more common in patients with PAD (odds ratio de- creased from 2.1 to 1.7 after performing multivariate analysis). Further, patients with PAD were less likely to have a diagnosis of cancer or benign strictures (Table 2). Stents were placed, replaced, and removed less frequently in patients with PAD (stent placement/replacement was reported in 280 [25.7\%] patients with PAD vs. 1,143 [35.0\%] in the controls $[p<0.001]$; stent removal was reported in 54 [4.9\%] in PAD vs. 265 [8.1\%] in the controls $[p=0.001])$.

The presence of PAD was associated with a shorter procedure time than that in the controls, but the groups had a similar fluoroscopy time (Fig. 2). After procedures where therapeutic success could not be established were removed, no difference was found in ERCP therapeutic success between the groups (94.9\% [691/728] in patients with PAD vs. $96.0 \%$ $[1,727 / 1,799]$ in the controls $[p=0.2])$. The presence of PAD did not decrease the visualization rates of the minor papilla (endoscopic view), common bile duct, or pancreatic duct (fluoroscopy). 
Table 3. Patient with Gallstone Disease Demographics, ERCP Indications and Success $(n=4,356)$

\begin{tabular}{|c|c|c|c|c|}
\hline & & $\begin{array}{c}\text { Periampullary diverticulum } \\
\text { and gallstones } \\
n=632(\%)\end{array}$ & $\begin{array}{c}\text { Controls with gallstones } \\
n=632(\%)\end{array}$ & $p$-value \\
\hline Age & Mean $y r \pm S D$ & $69.9 \pm 14.5$ & $69.9 \pm 14.5$ & - \\
\hline Gender & Male (\%) & $353(55.9)$ & $353(55.9)$ & - \\
\hline Ethnicity & $\begin{array}{l}\text { White } \\
\text { Black } \\
\text { Native American } \\
\text { Other }\end{array}$ & $\begin{array}{c}551(87.6) \\
13(2.1) \\
48(7.6) \\
20(3.2)\end{array}$ & $\begin{array}{c}560(88.7) \\
34(5.4) \\
25(3.9) \\
13(2.1)\end{array}$ & $<0.001$ \\
\hline ASA risk class & $\begin{array}{l}\text { I } \\
\text { II } \\
\text { III } \\
\text { IV-V }\end{array}$ & $\begin{array}{c}40(7.1) \\
309(54.6) \\
203(35.9) \\
14(2.5)\end{array}$ & $\begin{array}{c}58(10.7) \\
280(51.5) \\
183(33.6) \\
23(4.2)\end{array}$ & 0.06 \\
\hline Setting & $\begin{array}{l}\text { Outpatient } \\
\text { Inpatient ward } \\
\text { ICU }\end{array}$ & $\begin{array}{c}202(33.8) \\
372(62.2) \\
24(4.0)\end{array}$ & $\begin{array}{c}229(40.6) \\
313(55.5) \\
22(3.9)\end{array}$ & 0.05 \\
\hline Time & $\begin{array}{l}\text { Average procedure time (min) } \\
\text { Average fluoroscopy time (min) }\end{array}$ & $\begin{array}{l}39.1 \pm 25.4 \\
8.1 \pm 22.3\end{array}$ & $\begin{array}{c}40.6 \pm 23.3 \\
7.2 \pm 8.3\end{array}$ & $\begin{array}{l}0.3 \\
0.5\end{array}$ \\
\hline Common bile duct visualization & $\begin{array}{l}\text { Visualized } \\
\text { Not visualized } \\
\text { Not sought }\end{array}$ & $\begin{array}{c}630(99.7) \\
1(0.2) \\
1(0.2)\end{array}$ & $\begin{array}{c}624(98.7) \\
1(0.2) \\
7(1.1)\end{array}$ & 0.1 \\
\hline Pancreatic duct visualization & $\begin{array}{l}\text { Visualized } \\
\text { Not visualized } \\
\text { Not sought }\end{array}$ & $\begin{aligned} 168 & (28.8) \\
43 & (7.4) \\
372 & (63.8)\end{aligned}$ & $\begin{aligned} 148 & (26.7) \\
42 & (7.6) \\
365 & (65.7)\end{aligned}$ & 0.6 \\
\hline Minor papilla visualization & $\begin{array}{l}\text { Visualized } \\
\text { Not visualized } \\
\text { Not sought }\end{array}$ & $\begin{array}{c}46(10.7) \\
33(7.7) \\
350(81.6)\end{array}$ & $\begin{array}{c}41(9.2) \\
22(4.9) \\
383(85.8)\end{array}$ & 0.2 \\
\hline Sphincterotomy & Performed & $522(83.6)$ & $463(73.3)$ & $<0.001$ \\
\hline $\begin{array}{l}\text { ERCP } \\
\text { therapeutic success }\end{array}$ & $\begin{array}{l}\text { Successful } \\
\text { Unsuccessful } \\
\text { Cannot be established }\end{array}$ & $\begin{array}{c}437(69.2) \\
4(0.6) \\
191(30.2)\end{array}$ & $\begin{array}{l}381(60.3) \\
3(0.5) \\
248(39.2)\end{array}$ & 0.003 \\
\hline
\end{tabular}

ERCP, endoscopic retrograde cholangiopancreatography; SD, standard deviation; ASA, American Society of Anesthesiologists; ICU, intensive care unit.

${ }^{a)}$ Only 2 patients were considered Class V.

Table 2 depicts the crude and adjusted odds ratios with confidence intervals for parameters evaluated in patients with PAD. No differences were found in ERCP therapeutic success between the groups in the univariate or multivariate analysis. However, patients with PAD required a sphincterotomy more frequently than the controls did (Table 3).

\section{PAD and gallstone disease}

The secondary analysis did not show any difference between patients with PAD and gallstone disease and controls with gallstone disease in terms of procedure time or structure visualization (common bile duct, pancreatic duct, or minor papilla). After excluding cases where therapeutic success could not be established, similar success rates were observed in both groups (99.1\% [437/441] in patients with PAD vs. $99.2 \%$
[381/384] in the controls, $p=0.8$ ).

\section{DISCUSSION}

To our knowledge, this is the largest study to assess the effect of PAD in ERCP performance on the basis of a national US sample collected over 13 years. No significant difference was seen in ERCP performance between patients with PAD and the controls, after hospital setting, procedure duration, use of sphincterotomy, and two major indications (bile stone disease or stent-related procedures) were adjusted for.

Previous studies have shown lower, higher, and no differences in the cannulation or therapeutic success rates in patients with PAD in contrast to controls. ${ }^{2,4-6,9,10}$ The difference 
between the findings can be explained by the differences in publication year, study design, and patient selection criteria. Starting in 2004, two large retrospective studies and two prospective studies showed similar success rates in patients with PAD. ${ }^{2,5,6,10}$ The lower cannulation rates were attributed to the inability to detect the papilla in a substantial percentage of patients with PAD. After this subgroup of cases was excluded, no difference was found in cannulation, irrespective of the papilla location.

In the present study, the visualization rates of main structures (common bile duct and pancreatic duct) were acceptable and similar to those in previous studies (visualization of the minor papilla is shown for illustrative purposes only). ${ }^{3,6} \mathrm{PAD}$ prevalence was similar to that reported in the literature (4.7\% here, $3 \%-25 \%$ in published series $)^{2-4}$ suggesting an acceptable recording of PAD within the CORI database. A detailed description of the PAD subtypes (i.e., types A or B) was not available for a subgroup analysis. In general, type B PAD has been associated more frequently with cannulation failure. ${ }^{5}$ In patients with this condition, many endoscopists advocate for a partial or limited sphincterotomy (pre-cut technique). ${ }^{2,5}$ Chen et al. reported that endoscopic sphincterotomy is less effective than papillary balloon dilation in PAD. ${ }^{2}$ Similar complication rates were seen among patients who underwent regular sphincterotomy, limited sphincterotomy, and papillary balloon dilation. ${ }^{2}$ Thus, further research is needed to determine the best approach to remove gallstones in patients with different subtypes of PAD, although all options appear to be safe. ${ }^{2,5}$

Previous literature also shows that $\mathrm{PAD}$ promotes bile stone formation by interfering with biliary drainage. ${ }^{2,10}$ Considering the retrospective design and specific sample selection in the present study, we cannot address this point. However, biliary stone disease was twice more common in patients with PAD than in the controls. Compared to other large ERCP series, our study reported malignant obstructions and benign strictures less frequently. ${ }^{2}$ CORI does not record stone size, anatomic location, or degree of ductal dilation. These details can provide valuable information on the mechanisms underlying PAD-induced gallstones.

We observed a high number of patients having stents replaced or removed in the control group despite the exclusion criterion of second/repeated ERCP. This can be attributed to some patients having their first ERCP performed at another institution or before the CORI software was in use or different procedures recorded under different patient number identifiers.

Multiple factors influence endoscopic cannulation and therapeutic success. Clinical expertise gained from managing multiple cases improves endoscopists' performance. Patient-related variables such as patient position (e.g., prone vs. lateral) and previous surgeries are important predictors of cannulation success but could not be included in multivariate analysis (they were mentioned in $<15 \%$ of the CORI reports).

Our study has some limitations. It retrospectively compared total procedure time and fluoroscopy time but not cannulation time. Cannulation duration and success rates are probably better indicators of procedure complexity and difficulty in relation to PAD. Cannulation time represents only a small percentage of total procedure time, and group differences could be underestimated. CORI has been criticized for not being representative of endoscopic practice in the US, lack of image documentation, and incomplete patient history or procedure complications, all of which would have been useful for our assesment. ${ }^{12}$ Finally, therapeutic success was self-reported and could not be clearly established in one-third of the cases. There is a possibility that endoscopists over-report therapeutic success for PAD (e.g., failure to perform deep cannulation in PAD despite clearing the causative gallstones) and underreport success for other indications.

Despite these limitations, our analysis provides a snapshot of the largest endoscopy sample in the US. Along with recent retrospective and prospective studies, this matched case-control study confirms that PAD may not be considered a hinderance to the success of ERCP.

\section{Conflicts of Interest}

The authors have no financial conflicts of interest.

\section{Author Contributions}

\author{
Conceptualization: Juan E. Corral, Frank J. Lukens \\ Data curation: Omar Y. Mousa, Paul T. Kröner \\ Formal analysis: JEC, OYM, PTK \\ Investigation: JEC, PTK, OYM \\ Methodology: OYM, PTK \\ Softwate: PTK \\ Supervision: Victoria Gomez, FJL \\ Visualization: JEC \\ Writing-original draft: JEC \\ Writing-reviewing\&editing: JEC, VG, FJL
}

\section{Acknowledgements}

The Clinical Outcomes Research Initiative (CORI) v3 Database is supported by the National Institute of Diabetes and Digestive and Kidney Diseases (NIDDK). The data from the CORI database reported here were supplied by the NIDDK Central Repositories. This manuscript was not prepared in collaboration with the CORI group and does not necessarily reflect the opinions or views of the CORI group, the NIDDK Central Repositories, or the NIDDK.

\section{REFERENCES}

1. Christoforidis E, Goulimaris I, Kanellos I, Tsalis K, Dadoukis I. The role of juxtapapillary duodenal diverticula in biliary stone disease. Gastroin- 
test Endosc 2002;55:543-547.

2. Chen L, Xia L, Lu Y, Bie L, Gong B. Influence of periampullary diverticulum on the occurrence of pancreaticobiliary diseases and outcomes of endoscopic retrograde cholangiopancreatography. Eur J Gastroenterol Hepatol 2017;29:105-111.

3. Mohammad Alizadeh AH, Afzali ES, Shahnazi A, et al. ERCP features and outcome in patients with periampullary duodenal diverticulum. ISRN Gastroenterol 2013;2013:217261.

4. Vaira D, Dowsett JF, Hatfield AR, et al. Is duodenal diverticulum a risk factor for sphincterotomy? Gut 1989;30:939-942.

5. Panteris V, Vezakis A, Filippou G, Filippou D, Karamanolis D, Rizos S. Influence of juxtapapillary diverticula on the success or difficulty of cannulation and complication rate. Gastrointest Endosc 2008;68:903910

6. Tham TC, Kelly M. Association of periampullary duodenal diverticula with bile duct stones and with technical success of endoscopic retrograde cholangiopancreatography. Endoscopy 2004;36:1050-1053.

7. Boix J, Lorenzo-Zúñiga V, Añaños F, Domènech E, Morillas RM, Gassull MA. Impact of periampullary duodenal diverticula at endoscopic retrograde cholangiopancreatography: a proposed classification of periampullary duodenal diverticula. Surg Laparosc Endosc Percutan Tech 2006;16:208-211.

8. Cotton PB. Endoscopic management of bile duct stones; (apples and oranges). Gut 1984;25:587-597.

9. Lintott DJ, Ruddell WS, Axon AT. Pseudostone at ERCP due to juxtapapillary diverticulum. Clin Radiol 1981;32:173-176.

10. Katsinelos P, Chatzimavroudis G, Tziomalos K, et al. Impact of periampullary diverticula on the outcome and fluoroscopy time in endoscopic retrograde cholangiopancreatography. Hepatobiliary Pancreat Dis Int 2013;12:408-414.

11. NIDDK Central Repository. Clinical Outcomes Research Initiative (CORI) [Internet]. Bethesda (MD): National Institute of Diabetes and Digestive and Kidney Diseases; c2018 [cited 2018 Jul 16]. Available from: https://repository.niddk.nih.gov/studies/cori/.

12. Ramsey PJ, Shaib YH, Graham DY. Appropriate use or overutilization of the CORI database? Am J Gastroenterol 2009;104:785-786; author reply 786-787. 